\title{
Building Student Capacity for High Performance Teamwork
}

\section{Dr. Denny C. Davis P.E., Washington State University}

Dr. Davis is Emeritus Professor of Chemical Engineering and Bioengineering at Washington State University. For two decades he taught capstone design courses with multidisciplinary teams and developed instructional materials and assessments that enhance student team success. He is a Fellow of ASEE and an active consultant on engineering design education.

\section{Mr. Ronald R Ulseth P. E., Iron Range Engineering}

Ron Ulseth directs and instructs in the Iron Range Engineering program in Virginia, Minnesota and he teaches in the Itasca Community College engineering program in Grand Rapids, MN. He was instrumental in growing the Itasca program from 10 students in 1992 to 160 students in 2010. In 2009, he worked with a national development team of engineering educators to develop the 100\% PBL curriculum used in the Iron Range model. He has successfully acquired and managed over $\$ 10$ million in educational grants including as PI on 7 grants from NSF. He has been in the classroom, teaching more than 20 credits per year to engineering students for more than 20 years. His specific areas of expertise are in active learning, faculty development, and learning community development. He has been awarded the 2012 Progress Minnesota award, 2012 Labovitz Entrepreneurialism award, and 2012 Innovator of the Year award from the Rural Community College Alliance all for his work in developing the Iron Range Engineering program. His degrees are in civil engineering (B.S., University of North Dakota), and mechanical engineering (M.S., University of Central Florida). He is licensed as a professional engineer in the state of Minnesota 


\title{
Building Student Capacity for High Performance Teamwork
}

\begin{abstract}
It is generally known that effective teams produce outcomes that exceed those of the same individuals working in isolation. However, engineering graduates (and faculty) typically receive little instruction on how to develop a team from its formation to a state of high performance. Consequently, engineering student teams seldom perform to a level they could, and graduates are ill-prepared for a work environment in which they are expected to be members of productive cross-functional teams. This paper presents a conceptual framework for teamwork and defines six key principles embodied in this framework. It offers definitions of teamwork performances for both individuals and the entire team in four areas of performance: team relationships, joint work products, individual work products, and knowledge assets. A plan is presented for integrating teamwork development into an engineering program to prepare graduates for subsequent development of high performing teams in the professional workplace. A case is discussed to illustrate how team development is achieved in a project-based curriculum setting.
\end{abstract}

\section{Introduction}

The great engineering challenges of the twenty-first century are complex and multidisciplinary in nature [1]. Engineers engaged in addressing problems of societal concern that have economic impact will necessarily be members of multidisciplinary teams that bring diverse expertise and perspectives to the problem solving process. In general, a team is "a small number of people with complementary skills who are committed to a common purpose, set of performance goals, and approach for which they hold themselves mutually accountable." [2]

Teamwork is identified as one of the most important abilities sought by employers of engineers [3-4]. This skill need is reflected in ABET criteria for accrediting engineering programs: Programs must demonstrate that their students have "an ability to function on multidisciplinary teams." [5] To enable the success of their graduates and employers of their graduates, engineering programs must prepare and document that their graduates can effectively develop and consistently contribute value to multidisciplinary teams.

Teaching engineering students teamwork, although vital to success of the student and the program, is attempted in many different ways, with varied success. Because teamwork is built upon knowledge, attitudes, skills, and processes, the development of teamwork requires instructional practices such as the cognitive apprenticeship method that combines modeling, explanation, practice in a relevant context, feedback, and experimentation applied to teamwork [6]. Teamwork is also a working environment in which reflective practice and metacognition are vital [7-11]. Therefore, students must understand principles and attributes of effective teamwork, practice teamwork, receive feedback on teamwork, and adopt practices of self-monitoring and self-regulation in their teams. 
In this paper, the authors summarize principles of effective teamwork, present a conceptual model describing elements and interactions of elements in effective teams, offer definitions of desired performance for four areas of performance, and illustrate the roles of instructors who teach and coach teams. We end with a brief case description illustrating how teamwork can be integrated into the curriculum in conjunction with engineering projects. This paper is intended to guide instructors and coaches in the development of self-regulated high-performing teams.

\section{Teamwork Principles}

Overall, effective teams maintain an equilibrium between development of the team's effectiveness and completion of project requirements [4]. To accomplish the project requirements and get better at working with one another, teams must engage in both individual actions (member contributions) and shared actions (team processes). The quality and complexity of team processes and level of team member effort directly affect the quality of their project output [12-15]. Project achievement impacts team member motivation to invest effort in the team [16]. Team culture that exhibits respectful social interactions is also important to gaining engagement of team members in the team's work [17-18].

Katzenbach and Smith [2] (p. 113) summarize requirements of a good team as one that has: (a) shared leadership roles, (b) individual and mutual accountability, (c) specific team purpose that the team itself delivers, (d) collective work products, (e) active problem-solving meetings with open-ended discussion, (f) performance measured directly by assessing collective work products, and (g) discussions, decisions, and real work done together. They further state that "The best teams invest a tremendous amount of time and effort exploring, shaping, and agreeing on a purpose that belongs to them both collectively and individually" and they "transform their common purpose into specific performance goals . ..." Effective teams also develop strong commitment to a common approach to how they will work together. They agree on who will do particular jobs, how schedules will be set and adhered to, what skills need to be developed, how continued membership on the team is earned, and how the group will make and modify decisions. Further, every team member does equivalent amounts of real work, and teams hold themselves accountable. Team accountability is at the core of developing commitment and trust. Trust and commitment follow people working together toward a common objective. (p. 116)

Smith [4] (p. 30) states that effective teams have: (a) positive interdependence, (b) individual and group accountability, (c) promotive interaction, (d) teamwork skills, and (e) group processing. Good teams focus on a common goal or single product while each person takes responsibility for both their own work and that of the team. Teams work together doing real work, usually face-toface. Each person must possess key skills and practice them effectively: communication (esp. listening), decision making, problem solving, conflict management, and leadership. Successful teams also periodically reflect, celebrate, and problem solve to improve processes.

Additional authors identify a variety of attributes of effective teams:

- Collective decision making, collaboration/interchangeability, appreciation of conflicts/differences, balance of participation, focus on key goals and objectives, open communication, mutual support among members, and team spirit. [19] 
- Collaboration, communication, conflict management, and self management [20]

- Sharing of responsibilities and duties, performing different roles, analyzing ideas objectively, discerning feasible solutions, developing strategies for action, and building consensus [21]

- Strategies and skills for productive negotiation [22]

- Giving and receiving safe and constructive peer feedback [23-25]

- Reflection and self-assessment of teamwork [10, 26-27]

- Developing shared understanding of expected team interactions (roles/responsibilities, information sources, interaction patterns, communication channels, role interdependencies, and information flow). [28]

Davis et al. [9] summarized the many skills and attributes of effective teams into four areas of performance. Each area of performance is focused on producing a type of evidence of effective teamwork: team relationships, joint work products, individual work products, or knowledge assets. These areas are described below.

Area 1: Team relationships. Successful teams establish and maintain relationships that benefit all members and team performance. This requires that teams build an inclusive climate that supports fully engaged open contributions by all members. Effective teams achieve strong buyin and interdependence among members that promises individual and team success; they celebrate their successes. High performing teams are effective in identifying and resolving conflicts within the team to strengthen the team and draw maximum benefit from diverse perspectives of members.

Area 2: Joint work products. Successful teams produce substantive high quality work products when members work together. They establish shared (consensus) team goals that guide their work. They manage tasks associated with group work to achieve team goals. Their work products (decisions, ideas, artifacts, etc.) reflect support of one another and synergies from the expertise and perspectives of participating team members.

Area 3: Individual work products. Successful teams receive from each member substantive high quality work products aligned with team goals when team members work individually. To achieve team goals, the team will allocate work responsibilities to members consistent with member abilities, team needs, and work balance. Individual members will be accountable to deliver high quality work products meeting established deadlines and team standards. When necessary, members will support one another in developing essential competencies and in completing critical work.

Area 4: Knowledge assets. Successful teams document, communicate, and manage team information responsibly and effectively for accomplishing team goals. Members communicate among themselves in ways that empower one another to work knowledgeably and efficiently. They communicate with outside stakeholders in ways that protect confidential information while also enabling stakeholders to contribute appropriately to project success. Teams develop shared knowledge assets by documenting their processes, ideas, and achievements with detail and organization that enables verification and checking validity of accomplishments. 


\section{Teamwork Conceptual Model and Principles}

A conceptual model for teamwork is useful for discussing the multiple components of teamwork, explaining how they fit together to produce desired teamwork outputs, and determining how we might develop teamwork knowledge and skills in individuals. We propose a conceptual model for teamwork comprised of inputs, outputs, and team functions under control of the team, as shown in Figure 1. As noted previously, the work of a team focuses on two equally important achievements or outputs: team development (development of the team's effectiveness) and project completion (completion of the project or tasks assigned to the team). Team member inputs to teamwork are seen as individual contributions or shared processes orchestrated by the team. These inputs contribute to the four product-oriented team functions: building team relationships, producing joint work products, producing individual work products toward team goals, and managing team information or knowledge assets [9]. Contractual obligations and resource limitations (as managed by the team) direct how team functions are implemented, therefore influencing the team's success in achieving desired team development and project completion.

\section{IDEALS Teamwork Conceptual Framework}

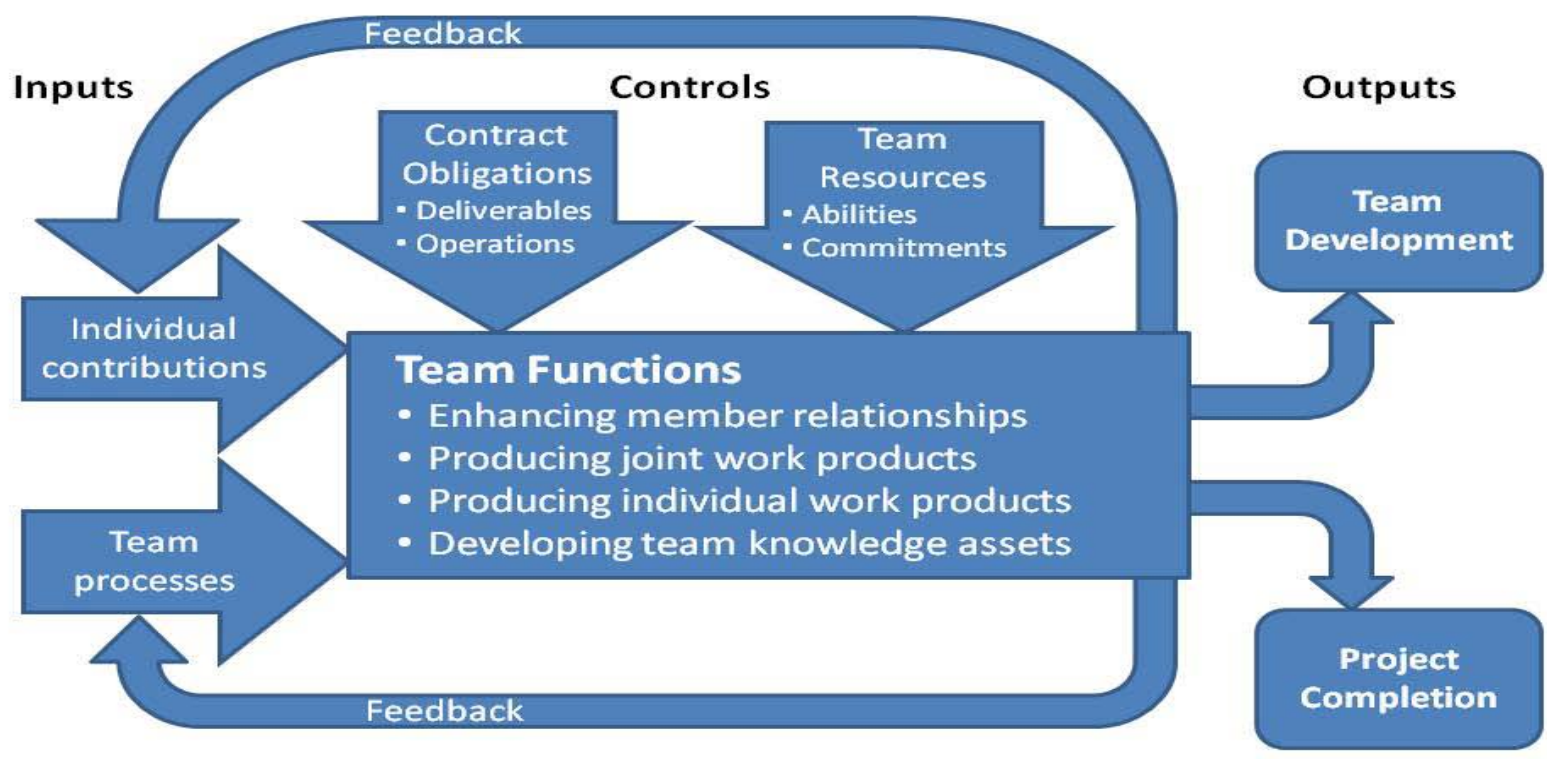

Figure 1. Conceptual Model for Teamwork 
This teamwork conceptual model can be summarized by the following learning outcome for teamwork:

In the context of team project work, team member behaviors and team processes contribute to constructive relationships, joint achievements, individual contributions, and information management that synergistically yield high team performance and successful project completion.

From consideration of the conceptual model, we can identify teamwork principles that need to be understood by those involved in teamwork as learners or as instructors/coaches. Key teamwork principles include the following.

Principle 1: Teams have dual goals. Teams must work to advance simultaneously both team development and project completion. Over emphasis of one at the cost of the other will reduce team achievement.

Principle 2: Teams need two types of inputs. Teams must ensure that sufficient, effective inputs are made through individual contributions and through team processes. A lack in one type of input can reduce effectiveness of the other.

Principle 3: Team improvement requires feedback. Teams must have mechanisms in place for providing feedback on performances. Because open-loop control systems (no feedback) become unstable, appropriate feedback is essential for consistent improvement.

Principle 4: Feedback requires performance definitions and assessment. Teams must define desired performances for team functions directed toward achieving team goals to enable assessment of these performances, which can guide improvement.

Principle 5: Members need accountability and authority. Team members must be held accountable for expected performances and must be given necessary authority to be successful.

Principle 6: Processes need definition and ownership. Team processes must be defined so all involved know the team's expectations. Someone must be responsible to monitor process effectiveness and to guide process improvements.

\section{Performance Definitions}

The teamwork conceptual model and teamwork principles highlight a need to establish definitions of desired teamwork performances that can inform learning and guide performance improvements. For greatest impact on learning and performance, performance definitions should be established by the people who will utilize them: design course instructors, team mentors, and student members of teams. By developing these definitions or reviewing and refining them, people gain understanding of the performances desired and take personal ownership for achieving them - both resulting in better performance of teamwork. 
Tables 1 through 4 present draft definitions of performances for the four areas of performance: team relationships, joint work products, individual work products, and knowledge assets. For each area, an overall performance is stated and this performance is expressed as multiple subperformances or performance indicators. For each performance indicator, specific performances are defined for team members as individuals (individual contributions) and for the team working together (team processes). These definitions provide performance descriptors for corresponding inputs to teamwork illustrated in the conceptual model for teamwork (Figure 1).

Table 1 defines performance expectations for efforts toward building team relationships - both individual contributions and team processes. Three sub-areas of performance for team relationships are: showing respect, demonstrating commitment, and resolving differences. Associated with each is a pair of individual contributions to that performance and a major team process. For example, showing respect for team members requires that each member give value to others' ideas and encourage each member to make contributions. In addition, the team should establish procedures (a team process) for facilitating discussions so that everyone contributes openly and receives positive reinforcement for contributions. These definitions should be reviewed and may be expanded or revised by a team to articulate the conditions expected in their team to gain full and risk-free participation from all members.

Table 1. Performance Expectations for Team Relationships

\begin{tabular}{|c|c|c|}
\hline Performance Indicator & Individual Contributions & Team Processes \\
\hline $\begin{array}{l}\text { Members show respect for } \\
\text { others on team }\end{array}$ & $\begin{array}{l}\text { - Members accept others' ideas } \\
\text { as having value } \\
\text { - Members encourage } \\
\text { everyone to share their ideas }\end{array}$ & $\begin{array}{l}\text { Discussion facilitation: } \\
\text { Discussions (face-to-face, } \\
\text { electronic, or other) are } \\
\text { moderated to obtain and give } \\
\text { merit to contributions from } \\
\text { everyone }\end{array}$ \\
\hline $\begin{array}{l}\text { Members demonstrate } \\
\text { commitment to team } \\
\text { success }\end{array}$ & $\begin{array}{l}\text { - Members exhibit pride in the } \\
\text { team and its successes } \\
\text { - Members contribute to a } \\
\text { strong team image/identity }\end{array}$ & $\begin{array}{l}\text { Celebration: The team regularly } \\
\text { celebrates and showcases } \\
\text { achievement of the team and } \\
\text { individual members }\end{array}$ \\
\hline $\begin{array}{l}\text { Members resolve } \\
\text { differences to benefit } \\
\text { entire team }\end{array}$ & $\begin{array}{l}\text { - Members commit to } \\
\text { resolving differences } \\
\text { constructively } \\
\text { - Members bring differences to } \\
\text { light for constructive } \\
\text { resolution }\end{array}$ & $\begin{array}{l}\text { Conflict resolution: The team } \\
\text { defines and implements a } \\
\text { process that identifies conflicts } \\
\text { early and negotiates resolutions } \\
\text { that benefit from diverse } \\
\text { perspectives }\end{array}$ \\
\hline
\end{tabular}

Table 2 defines performance expectations for working together toward joint work products individual contributions and team processes. Three sub-areas of performance for joint work products are developing shared goals, producing synergistic joint outcomes, and enabling all to 
contribute effectively in joint work. For example, developing shared goals requires individuals to cooperate in developing team goals that represent team consensus and then to refine personal goals so they align with (complement, do not contradict) team goals. Developing team goals also requires the team to manage their team goals in such a way that they are clear, helpful in guiding work of the team, used to monitor and direct team efforts, and responsive to changes that may occur over the duration of the project. Goals must be living and active, not dead on a shelf.

Table 2. Performance Expectations for Joint Work Products

\begin{tabular}{|c|c|c|}
\hline \multicolumn{3}{|c|}{$\begin{array}{l}\text { Joint Work Products: Teams produce substantive high quality work products when members } \\
\text { work together. }\end{array}$} \\
\hline Performance Indicator & Individual Contributions & Team Processes \\
\hline $\begin{array}{l}\text { Members contribute to } \\
\text { developing shared team } \\
\text { goals }\end{array}$ & $\begin{array}{l}\text { - Members help to establish } \\
\text { worthy consensus team goals } \\
\text { - Members align personal } \\
\text { goals with team goals }\end{array}$ & $\begin{array}{l}\text { Goal management: The team } \\
\text { establishes goals, uses them to } \\
\text { guide team efforts, monitors } \\
\text { progress, and revises goals as } \\
\text { necessary }\end{array}$ \\
\hline $\begin{array}{l}\text { Multiple members } \\
\text { produce joint outcomes } \\
\text { reflecting synergistic } \\
\text { inputs from everyone }\end{array}$ & $\begin{array}{l}\text { Members contribute effort, } \\
\text { knowledge, and skill needed } \\
\text { in joint work } \\
\text { - Members work for synergies } \\
\text { in joint work }\end{array}$ & $\begin{array}{l}\text { Collaboration management: } \\
\text { The team defines, follows, and } \\
\text { monitors procedures for } \\
\text { integrating components of joint } \\
\text { work products }\end{array}$ \\
\hline $\begin{array}{l}\text { Members enable one } \\
\text { another to contribute } \\
\text { effectively in joint work }\end{array}$ & $\begin{array}{l}\text { Members ask for help to be } \\
\text { more effective in joint work } \\
\text { - Members coach and engage } \\
\text { others to improve their } \\
\text { contributions in joint work }\end{array}$ & $\begin{array}{l}\text { Skill development: The team } \\
\text { identifies skill deficiencies and } \\
\text { seeks necessary training for } \\
\text { doing joint work }\end{array}$ \\
\hline
\end{tabular}

Table 3 defines performance expectations for contributions in support of developing individual work products - both individual contributions and team processes. Three sub-areas of performance toward individual work products are the allocation of responsibilities, fulfilling assigned work responsibilities, and pursuing resources to complete assigned work. To effectively allocate individual assignments, team members must sincerely accept assignments and ensure that they receive clear definitions of expectations for the assignment and have the authority they need to complete the assignment. The team must also establish procedures for making good work assignments, procedures that match team needs and member abilities and provide with the assignment clear definitions of expectations and any resources and authority needed to be successful. Additional expectations are defined for completing assignments and pursuing necessary resources. 
Table 3. Performance Expectations for Individual Work Products

\begin{tabular}{|l|l|l|}
\hline \multicolumn{3}{|l|}{ Individual Work Products: Teams receive substantive high quality work products aligned with } \\
team goals when team members work individually.
\end{tabular}

Table 4 defines performance expectations for contributions in support of communicating and managing team information or knowledge assets - both individual contributions and team processes. Three sub-areas of performance toward managing knowledge assets are communication with other team members, communicating with external stakeholders, and developing archival records that support team and project success. To effectively communicate within the team, individual members have responsibilities to consistently and completely keep other members informed of progress and concerns; in return they must also respond readily and fully to team member requests for necessary information. The team has the responsibility to establish consensus definitions of communication protocols among members, set up and implement tools specified by their protocols, monitor effectiveness of the protocols, and make revisions as needed. Additional individual and team responsibilities are defined for communicating with external stakeholders and for archiving team information. 
Table 4. Performance Expectations for Knowledge Assets

\begin{tabular}{|c|c|c|}
\hline \multicolumn{3}{|c|}{$\begin{array}{l}\text { Knowledge Assets: Teams document, communicate, and manage team information responsibly } \\
\text { and effectively for accomplishing team goals. }\end{array}$} \\
\hline Performance Indicator & Individual Contributions & Team Processes \\
\hline $\begin{array}{l}\text { Team members keep one } \\
\text { another fully informed }\end{array}$ & $\begin{array}{l}\text { - Members inform teammates } \\
\text { of progress and concerns } \\
\text { - Members respond to } \\
\text { teammate information } \\
\text { requests as needed }\end{array}$ & $\begin{array}{l}\text { In-team communication: The } \\
\text { team establishes, implements, } \\
\text { and revises as necessary } \\
\text { protocols and tools for } \\
\text { communication among members }\end{array}$ \\
\hline $\begin{array}{l}\text { Team members exchange } \\
\text { necessary information } \\
\text { with outsiders }\end{array}$ & $\begin{array}{l}\text { Members identify critical } \\
\text { information they need from } \\
\text { outside stakeholders } \\
\text { - Members provide necessary } \\
\text { information for reporting to } \\
\text { outside stakeholders }\end{array}$ & $\begin{array}{l}\text { External communication: The } \\
\text { team establishes, implements, } \\
\text { and revises as necessary } \\
\text { protocols for proper and timely } \\
\text { communication with clients and } \\
\text { others outside the team }\end{array}$ \\
\hline $\begin{array}{l}\text { Creating reliable records } \\
\text { of work and achievements } \\
\text { as knowledge assets }\end{array}$ & $\begin{array}{l}\text { Members fully document } \\
\text { their ideas, processes, and } \\
\text { work products } \\
\text { - Members share all of their } \\
\text { project documentation with } \\
\text { teammates }\end{array}$ & $\begin{array}{l}\text { Project documentation: The } \\
\text { team establishes, implements, } \\
\text { and revises as needed protocols } \\
\text { for documenting their processes } \\
\text { and work products and } \\
\text { controlling access to these assets }\end{array}$ \\
\hline
\end{tabular}

Roles and Responsibilities

Team member roles and responsibilities must be clearly defined to support team success [28-30]. For example, McGourty and De Meuse say that team meetings run more smoothly when four roles are assumed by various team members: primary facilitator, scribe, timekeeper, and secondary facilitator [24]. Clear definition of role expectations supports effective member interactions, interdependencies, and information flow, which enable teams to function effectively under rapidly changing conditions [28]. Descriptive definitions of performance also provide a sound basis for reliable peer assessment of teammate performances [31].

Roles are not the same as responsibilities, but they are related. Both are important to team performance and to member self-efficacy [18]. Here we define roles and responsibilities as:

- Roles are job titles or names given to the type of contribution a person makes (e.g., team leader, project manager, website developer, sponsor liaison)

- Responsibilities are lists of tasks for which a person is held accountable (e.g., posting meeting minutes within 12 hours of meeting adjournment, coordinating design activities associated with power system design, oversight of market research)

The teamwork conceptual model suggests that roles and responsibilities are important to successful teams whether they relate more to contributions of an individual or to managing 
processes that guide contributions of the team as a whole. In addition, every team member should be assigned roles associated with both team development and project completion so both outcomes are taken seriously by all members and both outcomes are accomplished well.

Table 5 presents examples of roles and responsibilities appropriate for team members. Meeting scribe and meeting facilitator roles support effective meetings, while chief engineer - power system and test engineer focus heavily on elements of project completion. The report manager role establishes processes, oversees work completion, and ensures quality of reports associated with project achievements. These role and responsibility definitions illustrate the types of information members need to effectively perform their respective roles. Teams must define roles and responsibilities with detail that enables members to understand the team's expectations of them.

Table 5. Example Roles and Responsibilities for Team Members

\begin{tabular}{|l|l|}
\hline Functional Role & Responsibilities \\
\hline Meeting Scribe: & - Distributes meeting notice (date, time, place, agenda) 5 days before meeting \\
Manages all & - Distributes information to be discussed in meeting 24 hours before meeting \\
communication & - Documents in meeting minutes: attendees, key elements of meeting \\
related to team & discussions, actions taken, assignments made, next meeting date and purpose \\
meetings & - Posts meeting minutes to team repository within 24 hours of meeting
\end{tabular}


The team performance definitions discussed provide a foundation for achieving strong team performances. These establish performance targets useful for communicating and discussing teamwork expectations. The next section describes instructional practices to help students develop the desired teamwork performances.

\section{Instructional Methods}

How does a faculty teach students teamwork in the context of their engineering degree program? Learning depends to a large extent on student motivation. Motivation is enhanced by linking learning to students' perceived needs for the future and by building students' confidence that they can succeed in learning [6]. Teaching teamwork in the context of authentic engineering projects motivates students, especially when their team performance will affect project success and their course grades. Teamwork must be evaluated along with other course outcomes if it is to be taken seriously by students.

Learning is enhanced when principles of how people learn are observed and when the instructional methods fit the type of learning being attempted. Key principles of learning include [32]:

- Establish and communicate clear learning outcomes

- Build on previous knowledge and correct misconceptions

- Provide and build on a framework that makes sense of the content

- Teach with context relevant to learners to motivate learning

- Use repetition to deepen learning and aid recall

- Provide regular and personalized feedback on learning

Teamwork learning includes gaining knowledge of what constitutes effective teamwork and developing skills needed to perform as an effective team. The cognitive apprenticeship method is an instructional method that models and coaches development of skills, such as teamwork, along with thinking processes that enable these performance skills. The instructor models teamwork behaviors and provides explanations for the behaviors, followed by the learner practicing the same behaviors and describing thinking processes in increasingly challenging environments. Steps in the cognitive apprenticeship method are [6]:

- Instructor demonstrates skill in a realistic context similar to that to be encountered in the future

- Instructor demonstrates and explains thinking processes associated with skill, including variations

- Learner practices skill in structured, coached environment

- Learner describes steps learned, for instructor checking

- Learner reflects on learning process to understand what helped and what hindered learning

- Learner is given more varied problems and identifies additional problems for which the skill is applicable 
The cognitive apprenticeship model is suitable for teaching many different skills that are part of teamwork: negotiation skills, team meeting facilitation skills, assignment allocation skills, idea documentation skills, and many others important to teamwork.

Teamwork Curriculum

A curriculum for teamwork development must fit within the framework of an engineering program curriculum and be situated among projects that motivate and authenticate the skills being developed. Consistent with requirements for developing expertise, students need repeated teamwork learning experiences and multiple project experiences to elevate their skills to higher levels [33]. The teamwork curriculum uses experiential learning as a process for constructing knowledge during a recursive or spiral learning cycle that includes experiencing, reflecting, thinking, and acting [34]. As stated by Davis et al (2011), teamwork learning is situated in a project setting and achieved through a reflective project-based learning cycle comprised of [35]:

- Encountering a teamwork challenge that hinders performance

- Identifying the problem and defining goals and an approach to resolve the problem

- Taking action to implement plans for resolving the teamwork problem

- Assessing success at achieving goals and revising plans to enhance team performance

- Thinking reflectively while practicing teamwork as best understood

- Performing teamwork based on rich understanding of teamwork

The Integrated Design Engineering Assessment and Learning System (IDEALS) provides instructional resources and assessments to facilitate the learning and assessment of essential teamwork planning, peer-review, process review, and performance documentation skills [36]. These resources can serve as cornerstones for a teamwork curriculum.

Teamwork curriculum planning begins with identification of teamwork principles and skills to be learned, identifying teamwork learning opportunities across the engineering program, identifying component skills for major learning goals, and allocating learning goals to different points in the curriculum. These steps are discussed below.

Teamwork Principles and Skills. Important teamwork skills and principles are defined earlier in this paper. This includes the conceptual model for teamwork showing relationships among teamwork inputs, function, outputs. It also includes definitions of member contributions and team processes that fall within the four categories of team relationships, joint contributions, individual contributions, and information management.

Teamwork Learning Opportunities. Teamwork learning is most effective when teamwork instruction, practice, and feedback are parts of the learning continuum from freshman to senior year. Opportunities that are relatively natural to engineering undergraduate programs are illustrated in Figure 2 - multiple team project experiences preceded by appropriate orientation. New student orientation to engineering programs offers an instructional opportunity for faculty to communicate to students the importance of teamwork and to identify teamwork principles that will be practiced in the program. Icebreaker activities for new students can be mini-projects for practicing team skills and reinforcing teamwork principles for eager learners. When students begin project-based learning experiences, whether as freshmen or more advanced students, their orientation to team projects should include additional content and skill-building exercises 
focused on teamwork development. Once engaged in team projects, the project mentors can systematically in team meetings prompt discussions of specific teamwork issues, coach the refinement of team skills, and provide feedback on teamwork observed. Particularly in multiterm projects, students can be given opportunities to self-assess and peer-assess teamwork and be prompted to establish habits of reflective practice with regard to teamwork development. Even as students gain team experience in different teams with different purposes, they will build upon previous knowledge, refine teamwork skills, and document increasing levels of teamwork performance over the duration of their engineering programs.

Specific suggestions for some of these teamwork learning opportunities are discussed in the following paragraphs.

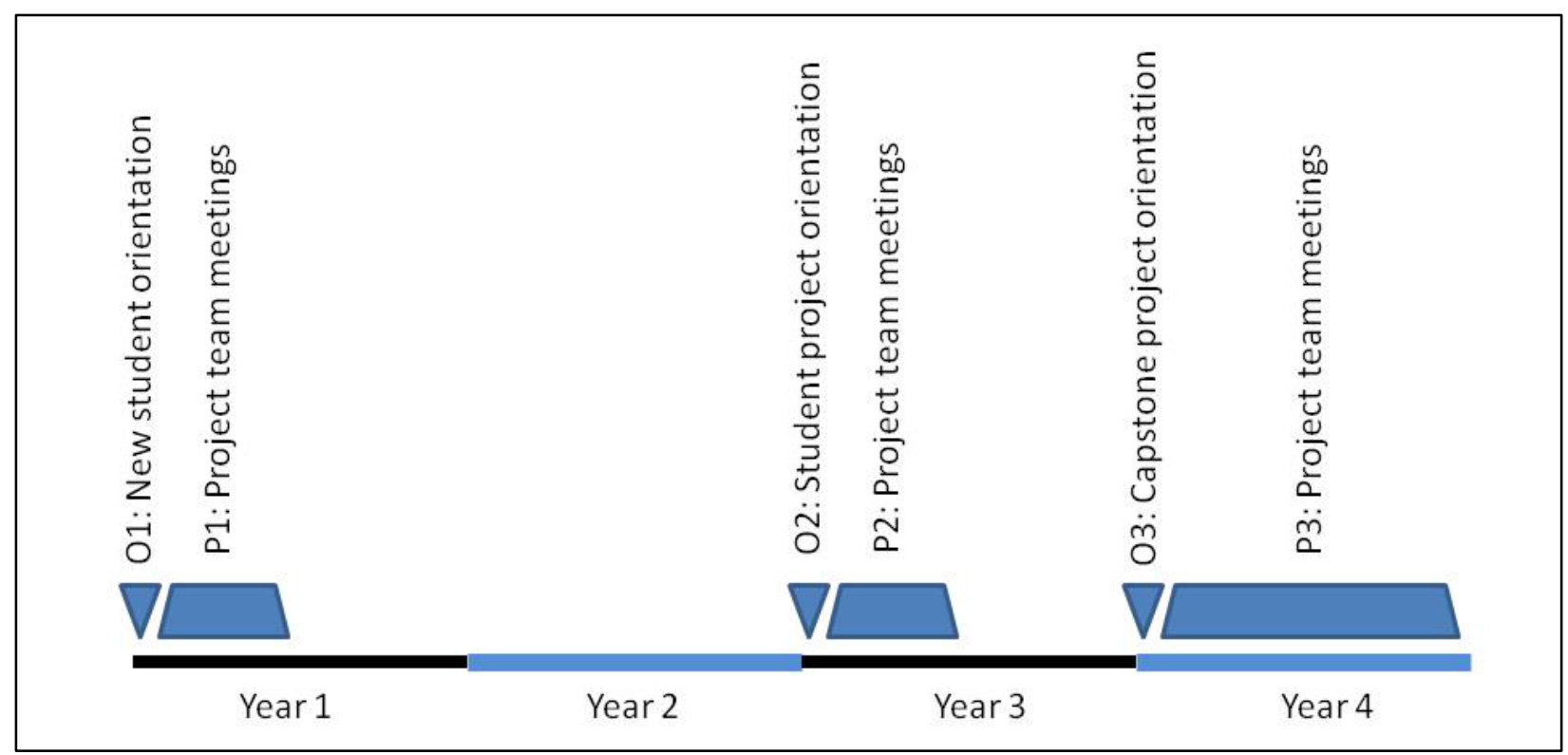

Figure 2. Teamwork Learning Opportunities across the Curriculum

Establishing Teamwork Expectations. Effective teamwork requires establishing desirable performance expectations that are shared by members of the team. Many students possess perceptions of teamwork based on their previous team experiences, observations of sports teams, and horror stories of teamwork. Team discussions of member expectations regarding teamwork will reveal these diverse perspectives and lay a foundation for developing shared expectations. Discussing expectations is a vital step for teams that will work together over any extended period of time.

Figure 3 presents a curriculum unit for developing shared understanding of teamwork and shared expectations of desirable team performances. Discussions facilitated in class or in meetings with teams are used to help students voice their perceptions and to generate team consensus for definitions of individual and team performances. Teams will identify outcomes for their team as 
well as lists of individual responsibilities and team processes needed for high performance of teamwork.

\section{Developing Shared Teamwork Expectations}

Purpose: Explore member understandings of teamwork and create a common set of performance expectations for members of a team.

Context: Use early in team formation for teams that will work together over a period of weeks.

Tasks: Facilitate the following discussions in teams, making clear that outcomes from these discussions will be a set of expectation for their own behaviors as a team.

1. [5 minutes with teams] Present to teams the IDEALS conceptual model (Figure 1) for teamwork. Ask each team to discuss the model and the outputs they expect from their team, as well as the inputs they provide to make the team successful. Ask each team to make revisions to the model that illustrate their understanding of teamwork.

2. [15 minutes with teams] Present to teams the four areas of performance (team relationships, joint work, individual work, and information management) presented in the teamwork conceptual model, and ask them to list specific products (results) that should come from their team for each of the four areas.

3. [20 minutes with teams, plus homework] Present to teams the concept that their teamwork depends upon individual contributions and team processes. Give teams examples of individual contributions and team processes for the four areas of performance (Tables 1-4) . Ask them to review this information, add performance indicators for an area, and define the corresponding individual contributions and team processes. As homework, the team should submit their revisions to the four tables.

4. [10 minutes with teams, after homework submitted] Ask teams to report on their homework assignment:

a. What new areas of performance did their team add to a table? What were the corresponding individual contributions and team processes?

b. Reflecting on the team's work for this assignment, what individual performances were used to produce team definitions of expectations?

Figure 3. Curriculum Unit for Defining Team Expectations

Team Roles and Responsibilities. An important part of teamwork is assigning members roles and responsibilities that support achievement of team goals. Students often are uncertain about the roles needed for a team, and sometimes they balk at assigning roles (e.g., leader) for fear of what they perceive the role to be. As stated earlier, shared leadership is important . . . but what does this mean? It is, therefore, vital to have productive discussions about roles and the proper responsibilities for those roles.

Figure 4 presents a curricular unit that can help students understand roles and responsibilities and select those appropriate for their team. 


\section{Defining Team Roles and Responsibilities}

Purpose: Clarify member understandings of roles and responsibilities and define responsibilities for key member roles on a team.

Context: Use early in team formation when teams are beginning to assign responsibilities to members.

Tasks: Facilitate the following discussions in teams, making clear that roles and responsibilities defined will be vital to their performance.

1. [5 minutes with teams] Review the teamwork conceptual model (Figure 1), noting the two types of outputs, four areas of performance, and two types of inputs.

2. [5 minutes with teams] Present to teams the reasons for roles and defined responsibilities on teams: accountability, efficiency, development of expertise, etc.

3. [15 minutes with teams, plus homework] Ask teams to review example roles and responsibilities (Table 5) and revise responsibilities as if for their team. Ask them to identify additional roles and define associated responsibilities for both individual contributions and managing team processes. Ask teams to complete this assignment, defining responsibilities for both individual contributions and team processes in all four areas of performance.

4. [After assignment submitted, 10 minutes with class] Ask teams to share with the class roles and responsibilities they defined. Facilitate class discussion about the value of each role for improving teamwork development and project completion.

Figure 4. Curriculum Unit for Defining Team Roles and Responsibilities

Team Operational Plan. Teams perform best when they operate according to understandings established by the entire team and which every member supports. Written "contracts" are helpful because they document the team members' intentions, which later may be remembered differently by individual members. A contract also calls for commitments of members (signees), which are vital to team success. A useful team contract will address issues that potentially can cause strife or inefficiencies: team purpose and goals, project scope and deliverables, member roles and responsibilities, delegation of authority and accountability, communication and project documentation protocols, ownership of team assets, etc. A team contract should be developed during the formation stage of the team, after the project is understood well enough to determine challenges and opportunities associated with the team and project.

Figure 5 presents a curriculum unit that can be used to guide students in the creation of a team contract or operational plan. Teams are guided to review team expectations, adopt those fitting their needs and preferences, and define these in contract language. Similarly, they select roles and define responsibilities of the role, identify individuals assigned each role, and add these to their contract. The contract provides the team a compact for governing themselves and provides 
the instructor a view into the team's philosophy, member interests and strengths, and negotiated understanding of teamwork.

\section{Creating a Team Contract}

Purpose: Develop and formalize an agreement among team members on goals, principles, structure, and responsibilities of team members.

Context: Use early in team formation but after teams have discussed performance expectations and roles appropriate for high performance teams.

Tasks: Facilitate the following discussions in teams, making clear that the contract they develop will be used to govern their actions and will be used to assess their understanding of teamwork.

1. [15 minutes with teams] Ask teams to compile a list of performance expectations they believe need to be followed and enforced in their team to reach a state of high performance.

Encourage them to draw from the individual contributions and team processes they discussed earlier.

2. [15 minutes] Ask students to identify member roles important to their team- roles related to both team development and project completion. Then ask them to define specific responsibilities associated with each role and to identify a person for each role. For critical roles, the team may want to identify a secondary person as well.

3. [5 minutes, plus homework] Ask students to prepare a written team contract, documenting consensus agreements on the team's operational plan. The contract should be a formal agreement that defines: team name, members, roles and responsibilities, important procedures to follow, accountability, and ownership of knowledge assets. The contract should address team relationships, work done together (e.g., meetings), work done alone (e.g., assignments and accountability), and communication and documentation expectations. The IDEALS Team Contract assessment (found at "http://ideals.tidee.org") may be set up by the instructor for team completion online.

Figure 5. Curriculum Unit for Creating a Team Contract

Team Member Feedback. Once a team is established and operational, it can benefit from feedback on individual member contributions. Feedback to members can help them better perform to the expectations of the team. Oftentimes, students are unaware of members' perceptions of their contributions, so they contribute based on incorrect information. In addition, students can benefit by learning how to give and receive constructive feedback; this makes them more aware of expectations and teaches them how to communicate effectively with teammates.

Figure 6 presents a curriculum unit for team members giving and receiving feedback on the contributions of each team member relative to their expectations. To prompt thinking about expectations, students are first asked to rate the importance of different kinds of member contributions. Then they are asked to rate each team member (including self) on twelve different types of contributions. They also identify their perceptions of each member's percentage 
contribution of the entire team effort. Finally, students are asked to write about a strength of each member and an area to improve. After each member submits feedback, each then receives an anonymous compilation of feedback directed to him or her. The instructor scores the quality of feedback given by each person and adds comments regarding this person's contributions.

\section{Providing Feedback on Member Contributions}

Purpose: Provide each team member feedback on his or her contributions to the team and provide members feedback on the coaching they provide teammates.

Context: Use after teams have worked together long enough to observe how members are contributing to the team's work (project completion and team development).

Tasks: Facilitate the following discussions in teams, making clear that the purpose of the exercise is to learn how to give and receive feedback that enhances member contributions to the team.

1. [15 minutes with teams] Ask teams to discuss issues related to giving and receiving feedback: what works and what does not work. Ask teams to create a list of guidelines they would use for asking teammates to give them feedback on their performance. Give teams examples of feedback give to students and ask them to critique it.

2. [5 minutes, plus homework] Assign students to complete the IDEALS Team Member Citizenship assessment, set up by the instructor online at "http://ideals.tidee.org". Instruct students to write high quality feedback that will benefit their teammates. The instructor scores the feedback based on its quality, not the positive or negative nature of the feedback.

Figure 6. Curriculum Unit for Giving Feedback on Team Member Contributions

Team Process Review. Feedback on the effectiveness of team processes is important to enabling the team to work productively and synergistically. Processes that place unnecessary barriers before members or that cause work inefficiencies should be revised. Team processes should be revisited when obvious problems occur and periodically to address less problematic processes that could by revision yield improved team performance. The review and revision of team processes should focus on improving achievements to either team development or project completion.

Figure 7 presents a curriculum unit that guides a review of team processes that may produce revisions to the team contract. Teams are asked to rate the effectiveness of some typical processes to help them see that processes often need refinement. Then they are asked to review each of their team processes and to make revisions that will make the processes more effective. This will likely lead to the need to update their team contract to reflect the revised processes. The instructor may make this assignment online and ask teams to document their process revisions and updated contract online, which provides valuable records of team development that give evidence of teamwork development. 


\section{Reviewing Team Processes}

Purpose: Revise team processes to achieve greater efficiencies, effectiveness, and satisfaction in efforts toward team development and project completion.

Context: Use after teams have gained experience with team processes to build team relationships, meet and work together, allocate and perform work individually, and communicate and document project work.

Tasks: Facilitate the following discussions in teams, making clear that the purpose of the exercise is to see how their processes may be made more effective and enjoyable.

1. [10 minutes with teams] Ask teams to discuss and rate the effectiveness of each of the following team processes (Ratings: very effective as is, reasonable but could be improved, struggling and needs improvement):

a. Building strong team identity and commitment

b. Making well-justified consensus team decisions

c. Managing individual work assignments

d. Keeping teammates fully informed

2. [5 minutes with teams, plus homework] Ask teams to review their team processes for effectiveness. Include processes that relate to team relationships, working together, individual work, and information management. If these processes are documented in their team contract, ask them to review and revise process definitions found there. This assignment may be done online using the Teamwork in Progress assessment in an assignment set up by the instructor at "http://ideals.tidee.org".

3. Provide written feedback online to teams that submit their team process reviews and revised team contract online. Score the quality of their team process revisions and offer suggestions to make additional process improvements.

Figure 7. Curriculum Unit for Reviewing and Revising Team Processes

Teamwork Evaluation. As teams approach completion of projects, they should be demonstrating teamwork at the highest levels they have achieved. This provides an opportunity to evaluate teamwork in each team as a basis for assigning grades on teamwork. If the teams are multidisciplinary, evidence can be used for ABET accreditation to show that students have "an ability to function on multidisciplinary teams." A summative assessment of teamwork achieved gives the students encouragement as they document gains in their teamwork knowledge, attitudes, and performances. It also provides instructors substantive evidence of levels of teamwork actually achieved in teams. 
Figure 8 presents a curricular unit that supports evaluation of team and member achievements in team development. Students individually submit online an assessment that addresses their attitudes toward teamwork, individual member contributions, team processes, and learning about teamwork. The instructor scores student submittals using a standard rubric provided, thereby providing an evaluation that can be compared across students, teams, classes, and years.

\section{Evaluating Teamwork Achieved}

Purpose: Evaluate final attitudes, understanding, and performances of team members and team process effectiveness as evidence of teamwork achieved.

Context: Use after teams have worked together for a significant period and achieved consistent performance toward goals of team development and project completion.

Tasks: Prepare students to give accurate evidence of their teamwork attitudes, knowledge, and performance for use in evaluating teamwork achieved.

1. [10 minutes with teams] Ask teams to identify three to five areas in which they experienced the greatest growth in teamwork. Suggest the following possible areas:

a. Learning how to work with different people

b. Learning to communicate in supportive ways

c. Being responsible to complete work as requested by others

d. Being able to lead others well

e. Documenting work so others can understand it

2. [5 minutes with teams] Ask teams to discuss what causes the growth. Was it any of these possible causes?

a. Feeling obligations to teammates

b. Feeling obligations to project stakeholders

c. Having committed to do a job or follow a process

3. [5 minutes with teams, plus homework] Ask students to individually complete as homework the Teamwork Achieved assessment set up by the instructor at:

"http://ideals.tidee.org". Students will indicate how their attitude about 12 teamwork areas changed while on the team, rate team members on their contributions and effort invested, describe a strong performance of each team member, describe a strong team process, and explain how learning about teamwork will be useful after this project. The instructor scores each student's submittal using a standard rubric.

Figure 8. Curriculum Unit for Evaluating Teamwork Achieved for Each Student

In summary, the teamwork curriculum is comprised of establishing expectations, developing an operational plan for the team, providing feedback on individual contributions and team processes, and final evaluation of teamwork achieved. Each of these topics may be addressed 
multiple times in a curriculum, the first time focusing on basic concepts, subsequent times looking at progress and adjusting both understanding and behaviors, and later making on-the-go reflections on teamwork and additional refinements. Repeated discussion of topics is essential to deepen knowledge and reinforce the importance of teamwork. Forcing students to reflect on their performances develops their skills in reflection and their habits of reflection-both of which prepare them for professional practice.

\section{Teamwork Development Example}

Principles for teamwork development are illustrated through a specific implementation of these materials in the curriculum of the Iron Range Engineering (IRE) program in Virginia, Minnesota. IRE is a $100 \%$ project based, upper division, Bachelor of Science in Engineering (BSE) curriculum [37]. Each semester of the two-year curriculum, students complete a design project for an industry client. The project serves as the platform for students' technical, design, and professional learning during the semester. Developing teamwork skills is an essential component of the professional learning in the IRE program.

IRE faculty implemented the teamwork curriculum model described in this paper for the first time during fall semester 2012. The implementation consisted of workshops presented by faculty members, mentor guided team formation and development, and team member feedback followed by self reflection. The following paragraphs provide additional details of this implementation.

Table 6 summarizes timing and resources used for implementing the teamwork development curriculum in the IRE problem-based learning (PBL) curriculum. At the beginning of the fall semester, just as teams were forming, students participated in an active-learning workshop facilitated by the lead faculty member for professional learning. During this 6-hour workshop, student groups brainstormed attributes of successful teams in each of the four team performance areas (team relationships, joint work products, individual work products, and knowledge assets). This led to discussion of attributes and establishment of a team contract defining consensus expectations for team members. Over the next several weeks, faculty members presented short workshops on focused teamwork skills, such as developing trust, conflict management, time management, and celebrating achievements. These discussions gave teams tools for developing stronger team cohesion, motivating engagement, and being productive. In the sixth week, team mentors discussed with teams issues related to giving feedback to teammates, and team members completed the Team Member Citizenship assessment to provide feedback to teammates. Feedback informed each member about the way their contributions are perceived by others and provided information to guide improved future contributions. In the tenth week, the team mentor guided a review of team processes to help teams improve their team contracts and use them more effectively to improve team performance. In the fourteenth week, the team mentor facilitated team discussions of team achievement and used the Teamwork Achieved assessment to document students' perceptions of their teamwork achieved. 
Table 6. Teamwork Development Activities in One Semester of PBL Curriculum

\begin{tabular}{|c|c|c|c|}
\hline Intervention & Tools Applied & $\begin{array}{l}\text { Week in } \\
\text { Semester }\end{array}$ & By Whom \\
\hline $\begin{array}{l}\text { Workshop } \\
\text { (total time } 6 \\
\text { hours) }\end{array}$ & $\begin{array}{l}\text { Utilizing active learning group methods, students } \\
\text { learned principles of effective teaming and } \\
\text { performance definition. Tools used: Developing } \\
\text { Shared Teamwork Expectations, Defining Team Roles } \\
\text { and Responsibilities, Creating Team Contract. }\end{array}$ & 1 & $\begin{array}{l}\text { Lead } \\
\text { Professionalism } \\
\text { Faculty Member }\end{array}$ \\
\hline $\begin{array}{l}\text { Principle } \\
\text { Reinforcement } \\
\text { (30 minute } \\
\text { sessions) }\end{array}$ & $\begin{array}{l}\text { A variety of faculty members presented short } \\
\text { workshops during weekly seminars on: team } \\
\text { leadership, timeline management, team building, } \\
\text { conflict management, building trust, recognition and } \\
\text { celebration and assessment. }\end{array}$ & $2,3,5,6,7,8$ & $\begin{array}{c}\text { Various Program } \\
\text { Mentors }\end{array}$ \\
\hline Feedback & $\begin{array}{l}\text { Team mentors led students in a discussion on the } \\
\text { value of peer feedback and the appropriate language } \\
\text { to use in giving feedback. Students then used the } \\
\text { IDEALS Team Member Citizenship assessment. Tool } \\
\text { used: Providing Feedback on Member Contributions }\end{array}$ & 6 & Team Mentor \\
\hline Review & $\begin{array}{l}\text { Team mentors guided students to analyze their team } \\
\text { processes for effectiveness. Processes deemed in need } \\
\text { of improving were modified. Students used IDEALS } \\
\text { Teamwork in Progress assessment. Tool used: } \\
\text { Reviewing Team Processes }\end{array}$ & 10 & Team Mentor \\
\hline Evaluation & $\begin{array}{l}\text { In the week leading up to project completion, team } \\
\text { mentors facilitated team analysis of growth, success, } \\
\text { and areas of both strong and weak performance. } \\
\text { Students utilized IDEALS Teamwork Achieved } \\
\text { Assessment. Tools used: Evaluating Teamwork } \\
\text { Achieved }\end{array}$ & 14 & Team Mentor \\
\hline
\end{tabular}

Results

The IDEALS teamwork curriculum has been implemented in part in capstone design courses at a number of institutions over recent years, as reported in other publications [10,30]. As discussed in this paper, it has been implemented more completely in the IRE problem-based learning program during academic year 2012-2013. Although extensive evaluation of the curriculum has not yet occurred, early evidence indicates that the curriculum is moderately effective for helping instructors teach teamwork and helping student develop teamwork skills.

From previous studies of IDEALS teamwork modules, the modules have been found to stimulate reflection and member behavior changes that enhance teamwork $[10,30]$. Twenty seven alumni from five institutions, a few months after graduation, responded to a questionnaire about the impacts of IDEALS teamwork modules on their preparation for professional practice. Of these, 85 percent indicated that IDEALS teamwork modules (26\% slightly, 52\% somewhat, 7\% greatly) enhanced their understanding of teamwork and grew their ability to perform effectively in future teams. Of 32 respondents who had completed IDEALS modules for teamwork and 
other professional skills, $83 \%$ indicated benefits in developing reflective practice: $25 \%$ slightly, $34 \%$ somewhat, and $24 \%$ greatly enhanced their understanding of reflective practice and grew their ability to think reflectively about professional work. These reported benefits occurred from varied implementations of modules by faculty familiar with the modules, but who did not use the full teamwork curriculum.

Feedback from Iron Range Engineering faculty who used the IDEALS teamwork curriculum over one semester illustrates benefits achieved by faculty who are only moderately familiar with the modules, but who had workshop training and the curriculum resources described in this paper available to them. In some cases, faculty did not set aside adequate time for students to complete assessments, for faculty to provide quality feedback, and for both to discuss findings and take appropriate actions. IRE faculty would rate their execution of the teamwork curriculum model as satisfactory - identifying needs and specific actions to improve their mentoring processes. The curriculum has given them the understanding and tools to be more effective, but they need more practice to refine their processes.

IRE faculty report that they have seen the benefits of the curriculum model in their students' work. At the end of each semester, each student prepares a personal improvement plan, a chapter of which focuses on teamwork. This document details learning experiences and goals achieved, identifies goals for the future semester, and proposes an action plan for achieving those goals. In the teamwork chapter, students reported positive joint work products and team relationships while also reporting needed growth in individual work products by some team members and in the documentation of knowledge assets. Enhanced student learning of teamwork is evident in the quality of language used by students to describe their achievements, needed growth, and plans for improvement.

Additional data was obtained by a survey of IRE faculty administered in March 2013 to determine the impacts of the training workshop (in August 2012) and curriculum on their mentoring of teams through one and a half semesters. When asked to "rate the impact of the teamwork mentoring training and curriculum on your ability to mentor teams," three indicated "moderately positive impact," one "very positive impact," and one "slightly positive impact." Lesser impact was reported by an individual with extensive industry experience. Impacts cited by mentors included: greater understanding of the need for teaching teaming, principles of teaming, tools for applying principles of teaming, roles in effective teams, characteristics of student teams, mentoring tools, and a conceptual framework for structuring teamwork understanding. Faculty valued having greater understanding of teamwork and having tools to enable them to mentor teams more effectively.

When asked to "rate how you believe the teamwork mentoring curriculum has affected the effectiveness of teams you mentored this year," three reported "moderately positive impact" and two reported "slightly positive impact." One person commented that understanding the importance of instruction on teamwork and knowing how to give such instruction are both vital to achieving stronger team performances. Additional responses identified impacts of the curriculum to include: students better able to speak about specific aspects of teamwork when discussing successes and failures, students more effectively informing teammates of work plans, and students demonstrating more varied leadership approaches in team meetings. Thus, mentors are able to see positive changes in student behaviors as a result of their mentoring on teamwork. 
Summary and Conclusions

Widespread acknowledgement that teamwork is important to engineering success has driven engineering faculty to give greater attention to developing team skills in engineering students. Engineering projects provide excellent context for motivating learning of teamwork and for teaching and assessing authentic teamwork skills. The teamwork mentoring model presented in this paper provides content and assessments that can support success for engineering faculty and project mentors engaging in the teamwork development challenge. However, just as students need to learn teamwork skills, instructors need to learn and develop strong performances in mentoring the development of teamwork skills in students.

The mentoring model for teamwork development identifies a conceptual framework for teamwork, which is essential for organizing students' knowledge about teamwork, upon which to build teamwork skills and expertise. Expertise and high performance teamwork are developed only after students have repeated opportunities to practice and reflect upon earlier learning. The example implementation of this model at the Iron Range Engineering program illustrates how a first stage of learning produces moderate impacts on understanding and behaviors. Students and instructors in early stages of development of their respective skills are making moderate progress but need additional time and practice to achieve high levels of performance. It is expected that repeated practice of teamwork skills, reflection on teamwork learning, and initiative to address areas needing improvement by students will yield a spiral of teamwork growth that reaches significant levels of expertise before graduation. This requires a corresponding spiral of practice, reflection, and improvement on the part of project mentors and instructors.

Teamwork curriculum materials described in this paper have been used successfully in varied project and class environments. IDEALS modules have produced benefits in students' teamwork abilities and their abilities to think reflectively. As suggested in this paper, teamwork development exercises spread over the curriculum will reap much deeper learning and lasting impacts of teamwork skills. For greatest success, faculty need to identify multiple places in their curricula in which project-based learning occurs and use these experiences optimally for developing students' teamwork skills. Repeated teamwork experiences with successively increased performance expectations, coupled with corresponding teamwork mentoring, will advance students toward becoming teamwork experts. These students will benefit from documented teamwork expertise, which also distinguishes the engineering program for recognitions by employers and for program accreditation. Students win; programs win; a global society wins!

\section{Acknowledgements}

The authors acknowledge support of the National Science Foundation for development of teamwork instructional materials and assessments as part of grant number DUE 1065486. 
References

1. National Academy of Engineering. Grand Challenges for Engineering. 2008 [cited 2008 November 15]; Available from: http://www.engineeringchallenges.org/

2. Katzenbach, J.R., and Douglas K. Smith, The Discipline of Teams, in Harvard Business Review. 1993. p. 111-120

3. Passow, H.J., Which ABET Competencies Do Engineering Graduates Find Most Important in their Work? Journal of Engineering Education, 2012. 101(1): p. 95-118

4. Smith, K.A., Teamwork and Project Management. Third Edition ed. Basic Engineering Series and Tools. 2007: McGraw-Hill

5. ABET, Criteria for Accrediting Engineering Programs. 2012: Baltimore, MD

6. Svinicki, M.D., Learning and Motivation in the Postsecondary Classroom. 2004, San Francisco, CA: Anker Publishing

7. Agogino, A., S. Song, and J. Hey, Triangulation of indicators of successful student design teams. International Journal of Engineering Education, 2006. 22(3): p. 617-625

8. Busseri, M.A. and J.M. Palmer, Improving teamwork: The effect of self-assessment on construction design teams. Design Studies, 2000. 21(3): p. 223-228

9. Davis, D., et al. Assessing design and reflective practice in capstone engineering design courses. in American Society for Engineering Education Annual Conference. 2009. Austin, Texas: American Society for Engineering Education

10. Gerlick, R., et al. Reflective Practices of Engineering Capstone Design Teams. in American Society for Engineering Education Annual Conference. 2010. Louisville, KY: American Society for Engineering Education

11. Valkenburg, R., Schon revised: Describing team designing with reflection-in-action. Proceedings of DTRS, 2001: p. 249-271

12. Marks, M.A., J.E. Mathieu, and S.J. Zaccaro, A temporally based framework and taxonomy of team processes. Academy of Management Review, 2001. 26(3): p. 356-376

13. Powers, T., et al. Assessing team functioning in engineering education. in American Society for Engineering Education Annual Conference \& Exposition. 2002. Montreal, Quebec

14. Upchurch, R.L. and J.E. Sims-Knight. Teaming assessment: Is there a connection between process and product? in Frontiers in Education Conference. 2004. Savannah, GA

15. Zafft, C.R., S.G. Adams, and G.S. Matkin, Measuring Leadership in Self-Managed Teams Using the Competing Values Framework. Journal of Engineering Education, 2009. 98(3): p. 273-282

16. Ulloa, B.R., et al. What motivates Engineering Students to Work in Teams? in American Society for Engineering Education Annual Conference. 2007. Honolulu, Hawaii

17. Tonso, K.L., Teams that work: Campus culture, engineer identity, and social interactions. Journal of Engineering Education, 1996. 95(1): p. 25-37

18. Yasar, S., et al. In Her Shoes: How Team Interactions Affect Engineering Self-Efficacy. in American Society for Engineering Education Annual Conference. 2007. Honolulu, Hawaii

19. Panitz, B., Team Players. ASEE Prism, 1997. 7(4)

20. Besterfield-Sacre, M. and et al. ABET outcomes defined within Bloom's and Krathwahl's taxonomies (untitled appendix). 2000 [cited; Available from: www.pitt.edu

21. Brackin, P. and J. Williams. Teaching and assessing team skills in a senior level design course. in American Society for Engineering Education Annual Conference \& Exposition. 2001 
22. Brereton, M.F., et al., Collaboration in design teams: How social interaction shapes the product, in Analysing Design Activity. 1996, John Wiley and Sons: Chichester

23. Dominick, P.G., R.R. Reilly, and J.W. McGourty, The effects of peer feedback on team member behavior. Group \& Organization Management, 1997. 22(4): p. 508-521

24. McGourty, J. and K.P. De Meuse, The team developer: An assessment and skill building program. 2001: John Wiley \& Sons

25. Van Wie, B.J., et al. Team Building in a Project-Based Learning Course. in American Society for Engineering Education Annual Conference. 2011. Vancouver, BC: ASEE

26. Hirsch, P.L. and A.F. McKenna, Using reflection to promote teamwork understanding in engineering design education. International Journal of Engineering Education, 2008. 24(2): p. 377-385

27. Imbrie, P.K., S.J. Maller, and J.C. Immekus. Assessing team effectiveness. in American Society for Engineering Education Annual Conference. 2005

28. Mathieu, J.E., et al., The influence of shared mental models on team process and performance. Journal of Applied Psychology, 2000. 85(2): p. 273-283

29. Adams, S. and B. Laksumanage, Building successful student teams in the engineering classroom. Journal of STEM Education, 2003. 4(3,4): p. 1-6

30. Davis, D., et al., Assessing Team Member Citizenship in Capstone Engineering Design Courses. International Journal of Engineering Education, 2010. 26(4): p. 1-13

31. Ohland, M.W. and R.A. Layton. Comparing the reliability of two peer evaluation instruments. in American Society for Engineering Education Annual Conference. 2000. St Louis, MO

32. National Research Council, How People Learn: Bridging Research and Practice. 1999, Washington, DC: National Academy Press

33. Litzinger, T.A., et al., Engineering Education and the Development of Expertise. Journal of Engineering Education, 2011. 100(1)

34. Kolb, A.Y. and D.A. Kolb, The Kolb Learning Style Inventory -- Version 3.1: 2005 Technical Specifications. 2005, Hay Group: Boston, MA 02116. p. 1-72

35. Davis, D.C., et al. IDEALS: A Model for Integrating Engineering Design Professional Skills Assessment and Learning in American Society for Engineering Education Annual Conference. 2011. Vancouver, BC Canada: ASEE

36. Trevisan, M., et al. Integrated Design Engineering Assessment and Learning System: Piloting Teamwork and Professional Skills Development Instructional Materials. in American Society for Engineering Education Annual Conference. 2012. San Antonio, TX: ASEE

37. Marra, R.M., et al., The Iron Range Engineering PBL Curriculum: How Students Adapt within PBL, in 3rd International Research Symposium on PBL. 2011: Coventry, U.K

38. Lebeau, J., et al., Industry Perspectives on the Integrated Design Engineering Assessment and Learning System for Professional Skills. International Journal Engineering Education, (in review) 